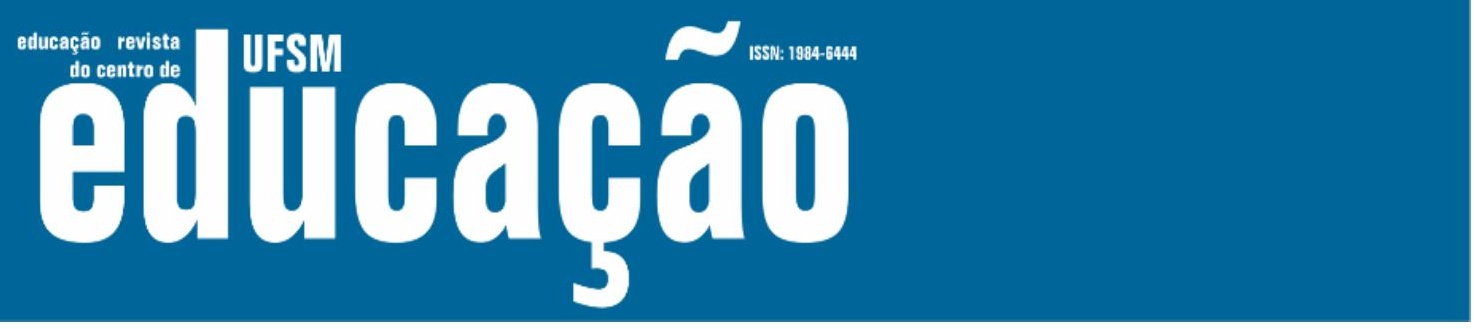

ISSN: 1984-6444 | http://dx.doi.org/10.5902/1984644436961

\title{
Revisão integrativa: intersectando concepções de educação ambiental com referencial teórico marxiano
}

Integrative review: intersecting conceptions of environmental education with a Marxian theoretical framework

\author{
Andreia de Bem Machado \\ Docente da Faculdade do Vale do Itajaí Mirim, Brusque, Santa Catarina e na Faculdade Municipal de \\ Palhoça, Palhoça, Santa Catarina, Brasil \\ andreiadebem@gmail.com - http://orcid.org/0000-0002-4404-0341
}

João Vicente Alfaya dos Santos

Doutorando do Programa de Pós-graduação em Educação da Universidade Federal de Santa

Catarina, Florianópolis, Santa Catarina, Brasil.

santosalfaya@gmail.com - https://orcid.org/0000-0001-5076-0831

Recebido em 12 de agosto de 2019

Aprovado em 08 de janeiro de 2020

Publicado em 24 de junho de 2020

\section{RESUMO}

O objetivo deste artigo é analisar à luz da revisão sistemática o conceito de educação ambiental intersectando concepções de educação ambiental com o referencial teórico marxiano. Para tanto, realizou-se a análise bibliométrica a partir de uma busca sistemática na base de dados Scopus. Como resultado, identificou-se que a pesquisa emerge da Medicina; Ciências Sociais; Ciência Ambiental; Ciências Agrárias e Biológicas; Energia; Bioquímica, Genética e Biologia Molecular; Psicologia; Engenharia; Artes e Humanidades; Enfermagem; Economia, Econometria e Finanças; Ciências da Terra e Planetárias; Profissões da Saúde; Matemática; Negócios, Gestão e Contabilidade; Química; Multidisciplinar; Imunologia e Microbiologia; Ciências da decisão; Farmacologia, Toxicologia e Farmacêutica; Física e Astronomia; Veterinária; Ciência da Computação; Ciência dos Materiais; Neurociência; Engenharia Química e Odontologia. A análise mostrou que embora a preocupação ambiental esteja nas mais diversas áreas, a contribuição do pensamento marxiano ainda não foi assimilada, mesmo entre aqueles que se dedicam à temática da educação ambiental em uma perspectiva "crítica". O que se constatou é que a questão ambiental e as propostas de educação ambiental são tratadas com viés idealista (mudança de valores, de comportamentos individuais) e politicista, relegando ao Estado e à vontade política o papel decisório sobre essa temática.

Palavras-chave: Educação ambiental; Conceito; Bibliometria, Marxismo. 


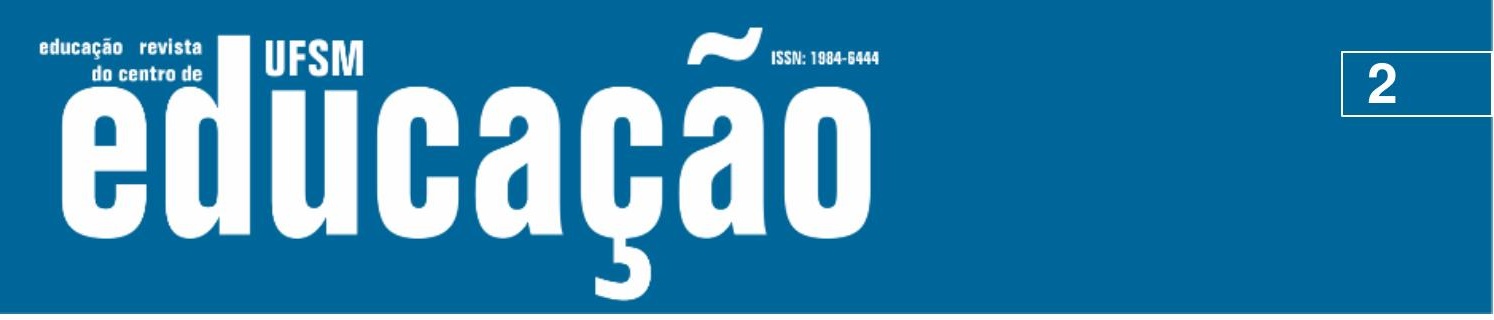

ISSN: 1984-6444 | http://dx.doi.org/10.5902/1984644436961

\section{ABSTRACT}

The objective of this article is to analyze in the light of the systematic review the concept of environmental education intersecting conceptions of environmental education with the Marxian theoretical reference. To do so, the bibliometric analysis was performed from a systematic search in the Scopus database. As a result, it has been identified that research emerges from Medicine; Social Sciences; Environmental Science; Agrarian and Biological Sciences; Energy; Biochemistry, Genetics and Molecular Biology; Psychology; Engineering; Arts and Humanities; Nursing; Economics, Econometrics and Finance; Earth and Planetary Sciences; Health Professions; Mathematics; Business, Management and Accounting; Chemistry; Multidisciplinary; Immunology and Microbiology; Decision sciences; Pharmacology, Toxicology and Pharmaceuticals; Physics and Astronomy; Veterinary; Computer science; Materials science; Neuroscience; Chemical Engineering and Dentistry. The analysis showed that although the environmental concernis in the most diverse areas, the contribution of Marxian thought has not yet been assimilated, even among those who dedicate themselves to the theme of environmental education in a "critical" perspective. What has been verified is that the environmental issue and the environmental education proposals are treated with an idealistic bias (change of values, of individual behaviors) and politicist, relegating to the State and to the political will the decisive role on this theme.

Keywords: Environmental education; Concept; Bibliometrics, Marxism

\section{Introdução}

Na década de 1970 iniciou-se uma preocupação dos governos e empresas manifestada pelas conferências, congressos internacionais, tratados, documentos legais e publicações com as questões relacionadas ao meio ambiente. Pode-se afirmar, sem correr o risco de uma simplificação excessiva, que as denúncias feitas por Rachel Carson, em seu livro Primavera silenciosa (2010), movimentou uma série de alertas ambientais. Essas denúncias encontraram eco nos movimentos ambientalistas, os quais passaram a ter, nos trabalhos de Rachel Carson e em outros pesquisadores, uma fundamentação científica para a temática ambiental. Essas inquietações foram gerando no cenário mundial conceitos relativos à educação ambiental. Um breve histórico da educação ambiental, bem como de marcos importantes do movimento ambientalista pode ser encontrado em Brügger (1999). No 


\section{F HES

ISSN: 1984-6444 | http://dx.doi.org/10.5902/1984644436961

Identificou-se que do universo de 390 trabalhos científicos, todos são artigos revisados por pares compondo a amostra para uma análise bibliométrica nas áreas humanas, ambiental e da saúde o que permite tecer o estado da arte dessa temática.

Para a apreciação bibliométrica dos resultados fez-se a exportação do resultado para um software de gerenciamento bibliográfico denominado EndNoteWeb (software baseado na Web) e de modo integrado trabalhou-se com a organização de uma planilha de dados. Assim, as informações relevantes foram classificadas de acordo com: distribuição temporal; principais autores, instituições e países em evidência; tipo de publicação na área; principais palavras-chave e trabalhos mais referenciados.

\section{Apresentação de dados e discussões}

Num primeiro momento analisou-se a distribuição temporal dos trabalhos identificando-se que as publicações foram bastante tímidas entre 1972 a 2007. Para melhor visualização elaborou-se o gráfico 1.

Gráfico 1 - distribuição temporal dos trabalhos

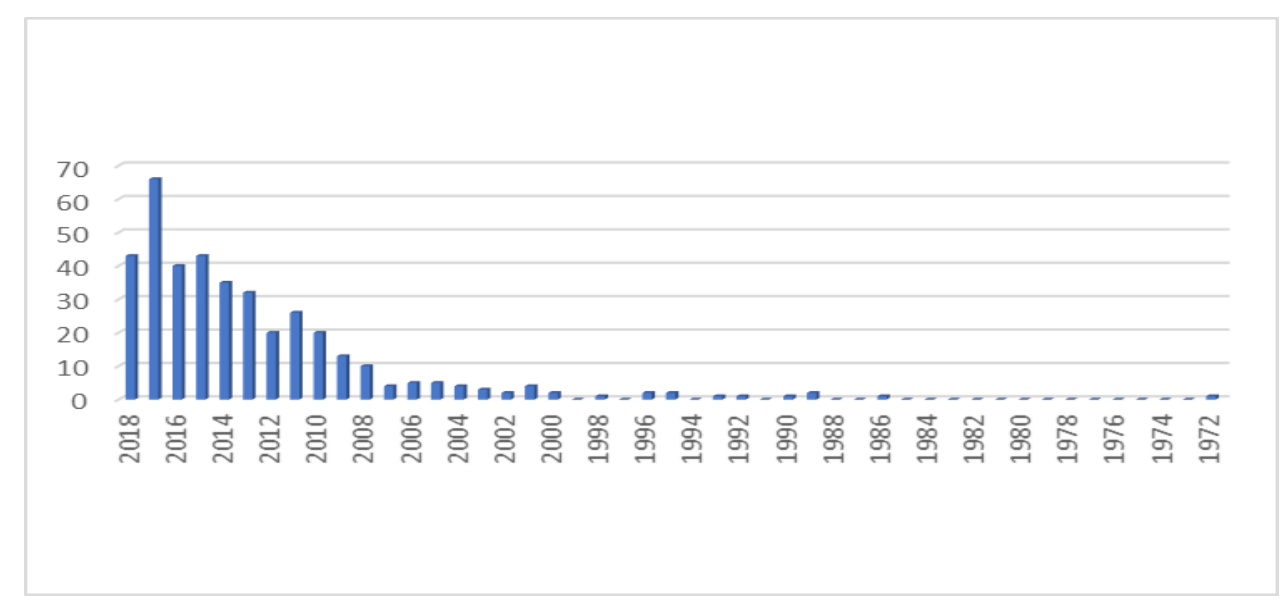

Fonte: Elaborado pelos autores (2019).

Foi identificado um trabalho como pioneiro intitulado Acceptance of disability of sudden onset in paraplegia dos autores Kerr, W.G., Thompson, M. A proposta do artigo era estudar sobre a aceitação da paraplegia em pacientes com a doença. Esse artigo 


\section{Wusm

ISSN: 1984-6444 | http://dx.doi.org/10.5902/1984644436961

não explicita um conceito de educação ambiental. Ele relaciona a questão do homem e as doenças com o meio ambiente.

Ao se analisar o país que mais tem publicação na área pode-se perceber que os Estados Unidos se destacam com uma média de $29 \%$ das publicações totais, um total de 104 trabalhos. Em segundo lugar destaca-se o Brasil com 10\% das publicações, ou seja, 37 trabalhos. O gráfico 2 demonstra os principais países envolvidos variando até os países que tem um mínimo de 11 publicações na área.

Gráfico 2 - distribuição por países dos trabalhos

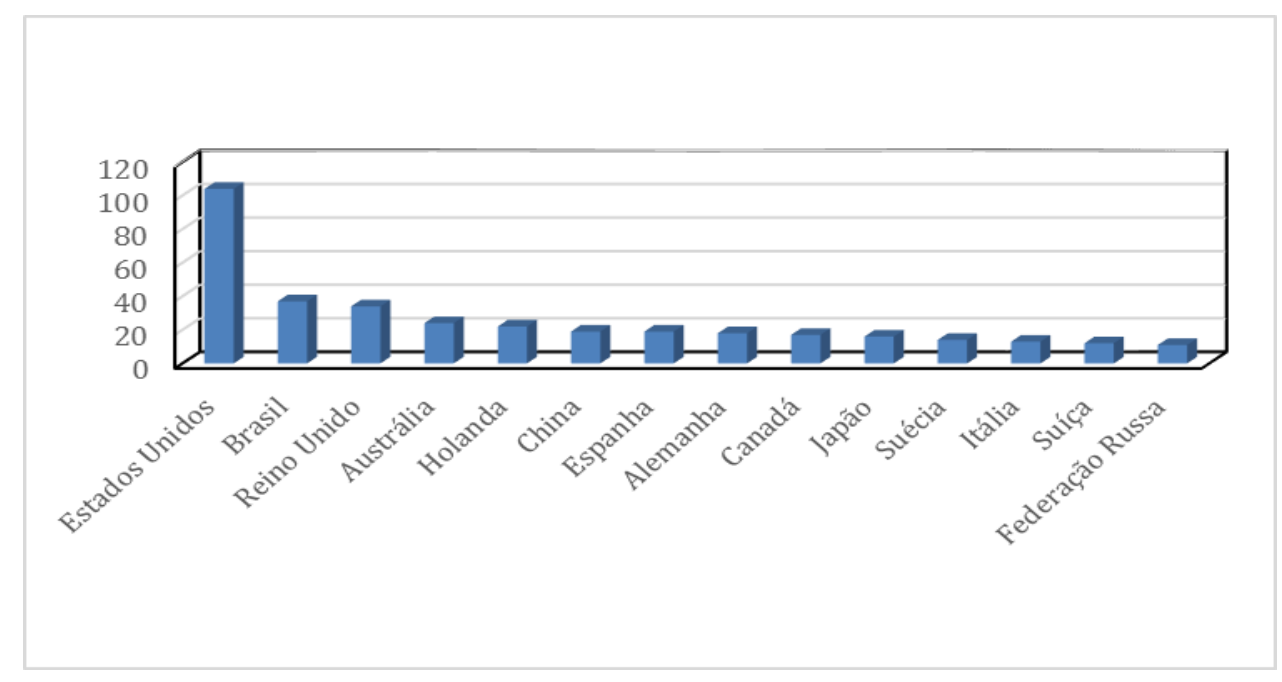

Fonte: Elaborado pelos autores (2019).

Outra análise realizada está relacionada à identificação de autores de destaque na área, onde se observou que um autor pode ser denominado como referência na área com três publicações, representadas no quadro a seguir: 


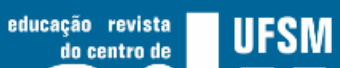

ISSN: 1984-6444 | http://dx.doi.org/10.5902/1984644436961

Quadro 2- Conceito de educação ambiental do autor referência

\begin{tabular}{|c|c|c|c|c|}
\hline Ano & Título original & Título traduzido & Autores & Resumo do artigo \\
\hline 2017 & $\begin{array}{c}\text { Screen-based } \\
\text { sedentary time: } \\
\text { Association with } \\
\text { soft drink } \\
\text { consumption and } \\
\text { the moderating } \\
\text { effect of parental } \\
\text { education in } \\
\text { Europeanchildren: } \\
\text { The ENERGY } \\
\text { study }\end{array}$ & $\begin{array}{l}\text { Tempo sedentário } \\
\text { baseado no } \\
\text { rastreio: } \\
\text { Associação com o } \\
\text { consumo de } \\
\text { refrigerantes e o } \\
\text { efeito moderador } \\
\text { da educação } \\
\text { parental em } \\
\text { crianças } \\
\text { europeias: o } \\
\text { estudo ENERGIA }\end{array}$ & $\begin{array}{l}\text { Gebremariam,M } \\
\text { K, Chinapaw, } \\
\text { MJ , Bringolf- } \\
\text { Isler, B, Bere, } \\
\text { E. , Kovacs, E., } \\
\text { Verloigne, M. h, } \\
\text { Stok, FM , } \\
\text { Manios, Y.j, } \\
\text { Brug, J., Lien, N. }\end{array}$ & $\begin{array}{l}\text { O objetivo do artigo era explorar } \\
\text { se as crianças que passam mais } \\
\text { tempo em comportamentos } \\
\text { sedentários baseados em tela (ou } \\
\text { seja, visualização de TV e uso do } \\
\text { computador) bebem mais } \\
\text { refrigerantes açucarados. }\end{array}$ \\
\hline 2006 & \begin{tabular}{|} 
Differences in fruit \\
and vegetable \\
intake and \\
determinants of \\
intakes between \\
children of Dutch \\
origin and non- \\
Western ethnic \\
minority children \\
in the Netherlands \\
- A cross sectional \\
study
\end{tabular} & $\begin{array}{l}\text { Diferenças no } \\
\text { consumo de } \\
\text { frutas e vegetais e } \\
\text { determinantes do } \\
\text { consumo entre } \\
\text { crianças de } \\
\text { origem holandesa } \\
\text { e crianças de } \\
\text { minorias étnicas } \\
\text { não ocidentais } \\
\text { nos Países } \\
\text { Baixos - Um } \\
\text { estudo transversal }\end{array}$ & $\begin{array}{c}\text { Velde, S.J., } \\
\text { Wind, M., van } \\
\text { Lenthe, F.J., } \\
\text { Klepp, K.-l., } \\
\text { Brug, J. }\end{array}$ & $\begin{array}{l}\text { O objetivo do artigo foi determinar } \\
\text { diferenças no consumo habitual de } \\
\text { frutas e vegetais entre crianças de } \\
\text { minorias étnicas holandesas e } \\
\text { não-ocidentais e estudar as } \\
\text { diferenças e os efeitos mediadores } \\
\text { de potenciais determinantes } \\
\text { psicossociais e ambientais. }\end{array}$ \\
\hline 2005 & $\begin{array}{c}\text { Why do } \\
\text { adolescents eat } \\
\text { what they eat? } \\
\text { Personal and } \\
\text { social } \\
\text { environmental } \\
\text { predictors of fruit, } \\
\text { snack and } \\
\text { breakfast } \\
\text { consumption } \\
\text { among 12-14- } \\
\text { year-old Dutch } \\
\text { students }\end{array}$ & $\begin{array}{c}\text { Por que os } \\
\text { adolescentes } \\
\text { comem o que } \\
\text { comem? } \\
\text { Preditores } \\
\text { ambientais e } \\
\text { sociais pessoais } \\
\text { do consumo de } \\
\text { frutas, lanches e } \\
\text { café da manhã } \\
\text { entre estudantes } \\
\text { holandeses de } 12 \\
\text { a } 14 \text { anos de } \\
\text { idade }\end{array}$ & $\begin{array}{c}\text { Martens, MK, } \\
\text { Van Assema, P. , } \\
\text { Brug, J. }\end{array}$ & $\begin{array}{l}\text { O objetivo do estudo foi investigar } \\
\text { a importância relativa dos } \\
\text { preditores pessoais e } \\
\text { socioambientais do consumo de } \\
\text { frutas, lanches ricos em gordura e } \\
\text { café da manhã. }\end{array}$ \\
\hline
\end{tabular}

Fonte: Elaborado pelos autores (2019).

Observa-se que as questões discutidas pelos autores sobre educação ambiental estão atreladas a questões referentes a saúde do ser humano relacionada aos hábitos alimentares.

Com base no levantamento geral, foi possível analisar ainda as áreas de concentração dos artigos que estão nos seguintes campos do conhecimento a saber: 


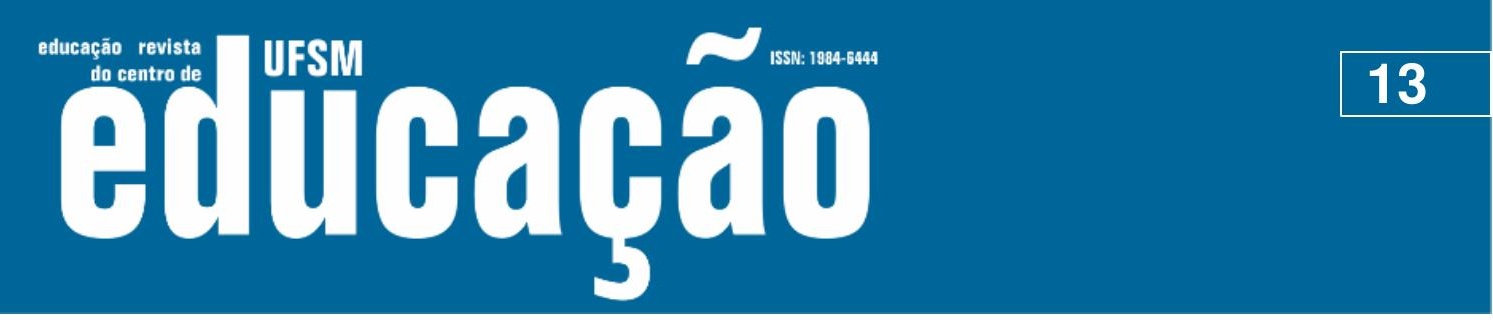

ISSN: 1984-6444 | http://dx.doi.org/10.5902/1984644436961

sustentável, que, mais de um século após a afirmação marxiana, ganhou grande destaque tanto na formulação de políticas, acordos internacionais e foi incorporado pelo discurso ecológico/ambiental oficial. Diz Marx:

Do ponto de vista de uma formação econômica superior da sociedade, a propriedade privada do globo terrestre nas mãos de indivíduos isolados parecerá tão absurda quanto a propriedade privada de um ser humano sobre outro ser humano. Mesmo uma sociedade inteira, uma nação, ou, ainda mais, todas as sociedades contemporâneas reunidas não são proprietárias da Terra. São apenas possuidoras, usufrutuárias dela, e, como boni patres famílias [bons pais de famílias], devem legá-la melhorada às gerações seguintes (MARX, 2017b, p. 836) ${ }^{2}$.

Todavia, não é apenas nessa constatação do ser humano como um ser também natural e do conceito de desenvolvimento sustentável (muito embora Marx não tenha se referido nesses termos) que reside a importância do marxismo para o pensamento ambiental. E aqui entra-se no segundo ponto, de que o marxismo, preocupado unicamente com a emancipação humana, veria na natureza apenas um elemento a ser subjugado pela técnica. Se é verdade que Engels, em especial, se admirava com o progresso do conhecimento e da indústria, não é menos verdade que esse progresso não ocorre sem custos da própria natureza e, por extensão, ao ser humano.

\footnotetext{
Mas não nos regozijemos demasiadamente em face dessas vitórias humanas sobre a Natureza. A cada uma dessas vitórias, ela exerce a sua vingança. Cada uma delas, na verdade, produz, em primeiro lugar, certas consequências com que podemos contar; mas em segundo e terceiro lugares, produz outras muito diferentes, não previstas, que quase sempre anulam essas primeiras consequências. Os homens que na Mesopotâmia, na Grécia, na Ásia Menor e noutras partes destruíram os bosques, para obter terra arável, não podiam imaginar que, dessa forma, estavam dando origem à atual desolação dessas terras ao despojá-la de seus bosques, isto é, dos centros de captação e acumulação de umidade. [...] E assim, somos a cada passo advertidos de que não podemos dominar a Natureza como um conquistador domina um povo estrangeiro, como alguém situado fora da Natureza; mas sim que lhe pertencemos, com a nossa carne, nosso sangue, nosso cérebro; que estamos no meio dela; e que todo o nosso domínio sobre ela consiste na vantagem que levamos sobre os demais seres de poder chegar a conhecer suas leis aplicá-las corretamente (ENGELS, 1979, p. 223224).
} 


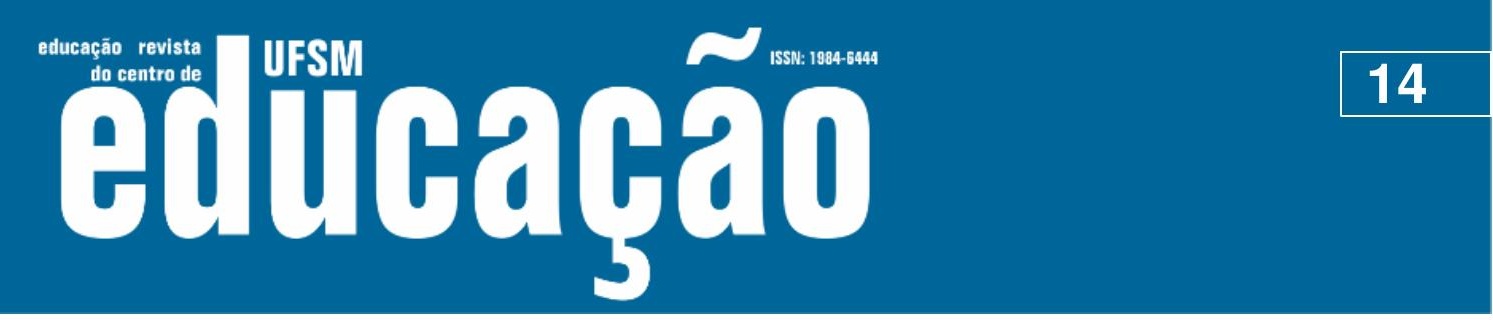

ISSN: 1984-6444 | http://dx.doi.org/10.5902/1984644436961

E em O Capital Marx afirma:

E todo o progresso da agricultura capitalista é um progresso na arte de saquear não só o trabalhador, mas também o solo, pois cada progresso alcançado no aumento da fertilidade do solo por certo período é ao mesmo tempo um progresso no esgotamento das fontes duradouras dessa fertilidade. Quanto mais um país, como os Estados Unidos da América do Norte, tem na grande indústria o ponto de partida de seu desenvolvimento, tanto mais rápido se mostra esse processo de destruição. Por isso, a produção capitalista só desenvolve a técnica e a combinação do processo de produção social na medida em que solapa os mananciais de toda a riqueza: a terra e o trabalhador (MARX, 2017a, p. 573-574).

Pode-se ver assim, em Marx, o que Bensaïd (2013) sintetizou acerca da questão ambiental, que ele não é nem um anjo verde, nem um demônio produtivista. Se, por um lado, ele estava consciente de que o ser humano para poder existir necessita se apropriar dos meios necessários à sua subsistência, e que esses meios provêm da natureza, ao mesmo tempo a forma como eles são extraídos trazem consequências, em maior ou menor grau, para a própria fonte desses meios. Essa concepção está atrelada ao artigo publicado em 2018, de Kahn, Weiss e Harrington que explicita em seu artigo intitulado "Modeling child-nature interaction in a nature preschool: A proof of concept" que o conceito de educação ambiental está relacionado a interação da natureza e o ser humano.

Analisando a questão da educação ambiental, tomou-se como base o trabalho de Layrargues e Lima (2014). Escolhemos este trabalho por ele fazer uma síntese das principais vertentes teóricas da educação ambiental. Neste trabalho apontam-se as três principais tendências na educação ambiental, a saber, a conservacionista, a pragmática e a crítica. Explicita-se um pouco mais o que são essas tendências a seguir.

Segundo a tendência conservacionista, há uma separação profunda entre sociedade e natureza, sendo que o ser humano, não raro, é comparado a um vírus destruidor que se propaga sobre a superfície do planeta, ou, para usarmos a metáfora de Pinker (2018), essa tendência concebe "uma imagem da Terra como uma donzela virginal que foi violada pela rapacidade humana" (p. 155). Em virtude disso, o que cabe ao ser humano é preservar, o máximo possível, os recursos naturais, mantendo 


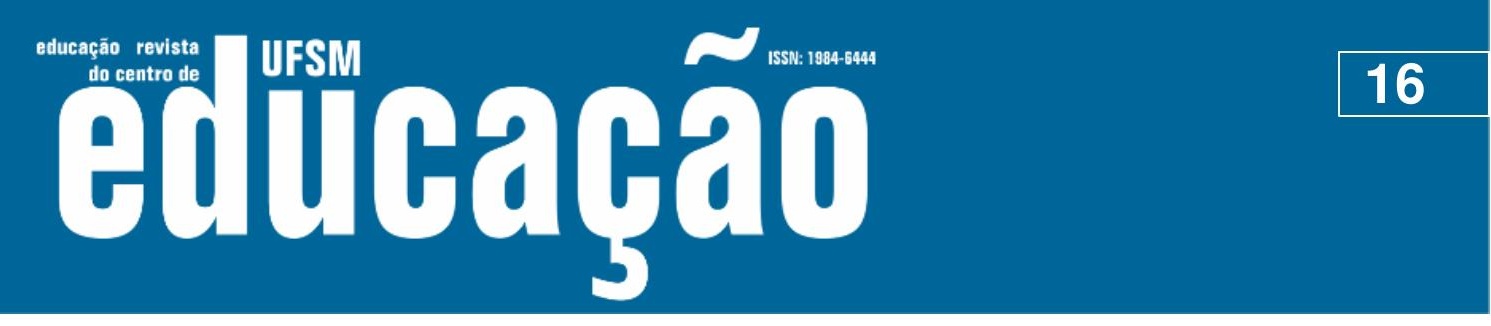

ISSN: 1984-6444 | http://dx.doi.org/10.5902/1984644436961

enfrentamento político das desigualdades e da injustiça socioambiental" (LAYRARGUES, LIMA, 2014, p. 33). É necessária uma citação longa do trabalho desses autores para justificar como, na visão deles, a educação ambiental crítica se diferenciaria das demais educações ambientais não críticas.

Assim como no ambientalismo, há um forte viés sociológico e político na
macrotendência crítica da Educação Ambiental, e em decorrência dessa
perspectiva, conceitos-chave como Cidadania, Democracia, Participação,
Emancipação, Conflito, Justiça Ambiental e Transformação Social são
introduzidos no debate. Não por acaso, o surgimento e consolidação dessa
macrotendência coincidem com o movimento ocorrido na Ecologia Política
como possibilidade de interpretação do ambientalismo. Além dessa preocupação política, a Educação Ambiental Crítica tende a conjugar-se com o pensamento da complexidade ao perceber que as questões contemporâneas, como é o caso da questão ambiental, não encontram respostas em soluções reducionistas. Daí seu potencial para ressignificar falsas dualidades que o paradigma cartesiano inseriu nas relações entre indivíduo e sociedade, sujeito e objeto do conhecimento, saber e poder, natureza e cultura, ética e técnica, entre outras dualidades. Mais recentemente, setores do pensamento ambiental crítico compreenderam que os reducionismos são empobrecedores, inclusive os sociologismos e politicismos. Por essa perspectiva complexa torna-se não só possível como necessária a incorporação das questões culturais, individuais e subjetivas que emergem com as transformações das sociedades contemporâneas, a ressignificação da noção de política, a politização da vida cotidiana e da esfera privada, expressas nos novos movimentos sociais e na gênese do próprio ambientalismo. As dimensões política e social da educação e da vida humana são fundamentais para sua compreensão, mas elas não existem separadas da existência dos indivíduos, de seus valores, crenças e subjetividades (idem, ibidem)

Atenhamo-nos aos conceitos-chave, que, segundo os autores, diferenciaria a pauta da educação ambiental crítica das demais modalidades de educação ambiental. Cidadania, democracia, emancipação e justiça ambiental. Todos valores que, sem dúvida, consideram-se como positivos. No entanto, esses valores são típicos da sociedade capitalista ${ }^{3}$ e, imbuídos neles, estão presentes dois elementos que gostaríamos de destacar: o primeiro deles, o idealismo; e o segundo o politicismo. Explicar-se-á mais adiante o sentido de politicismo aqui adotado para que não se confunda com o reducionismo a que os autores na citação se referem.

Comecemos pelo idealismo. Já é sobejamente conhecida a passagem de Marx (2008) na qual ele se refere que "não é consciência dos homens que determina o seu ser; ao contrário, é o seu ser social que determina sua consciência" (p. 49). Dela 


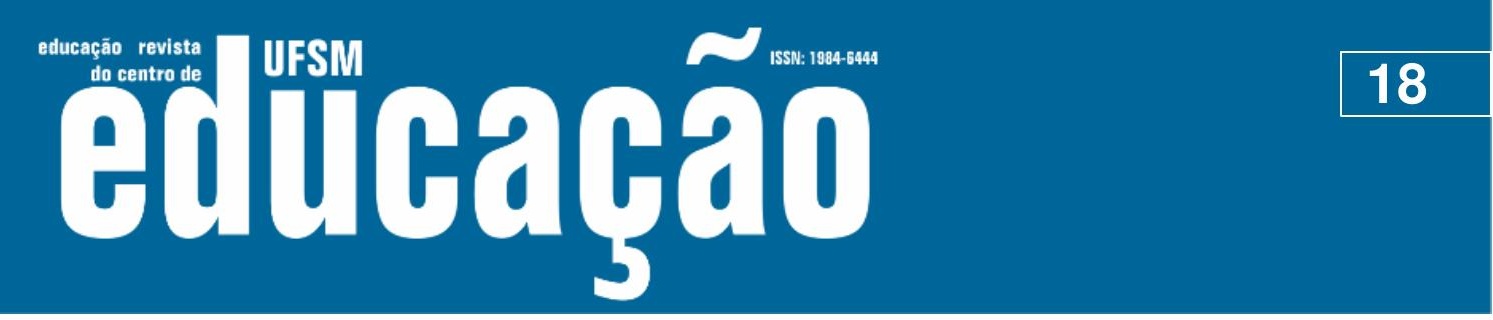

ISSN: 1984-6444 | http://dx.doi.org/10.5902/1984644436961

ressalta nos Manuscritos, o indivíduo é o ser social, mesmo que a atividade que exerça aparente ser algo desprovido de nexo com outros indivíduos.

Mas mesmo quando estou cientificamente ativo etc., uma atividade que eu
raramente posso executar em comunidade imediata com outros, estou
socialmente ativo, porque [ativo] como homem. Não só o material da minha
atividade - como a própria língua na qual o pensador é ativo - me é dado
como produto social, a minha existência própria é atividade social. [...] A vida
individual e a vida genérica do homem não são diversas, por muito que - e
isso necessariamente - o modo de existência da vida individual seja um modo
mais particular ou mais universal da vida genérica, ou por mais que a vida
genérica seja uma vida individual mais particular ou mais universal (MARX,
2015, p. 347-348).

Com isso, se esmorece qualquer prioridade ontológica dos indivíduos em face da sociedade. O ser humano só se torna ser humano se se apropriar do conjunto das objetivações (transformações através do ato de trabalho), do patrimônio cultural produzido e acumulado pelo conjunto dos homens em uma determinada época histórica. É através da relação dialética entre apropriação e objetivação que o ser humano se forma, se educa ${ }^{5}$. Isso tem implicações amplas para as questões educacionais e políticas. Não há uma essência humana, seja ela boa ou ruim, preexistente à própria humanidade. O homem não é egoísta por natureza, são as relações sociais que, sendo desumanizadas, produzem indivíduos egoístas, desumanizados.

Todavia, se fica claro que a pergunta pelo que veio primeiro, se o indivíduo ou a sociedade, é uma pergunta equivocada, isso não significa que não haja um momento predominante na interação entre os indivíduos singulares e a totalidade social. $E$ isso nos remete de volta a afirmação de que é o ser social que determina a consciência, e não o contrário.

Os homens fazem a sua própria história; contudo, não a fazem de livre e espontânea vontade, pois não são eles quem escolhem as circunstâncias sob as quais é feita, mas estas Ihes foram transmitidas assim como se encontram. A tradição de todas as gerações passadas é como um pesadelo que comprime o cérebro dos vivos (MARX, 2011, p. 25).

Esse é um ponto chave para pensar a educação e a educação ambiental em específico. Vive-se no momento histórico da sociedade capitalista, que possui uma dinâmica complexa, estudada objetivamente por Marx, desde suas obras de juventude, mas com especial destaque para sua produção madura, O Capital. Essa 


\section{U Lism eltioará

ISSN: 1984-6444 | http://dx.doi.org/10.5902/1984644436961

sociedade tem leis que regem a sua dinâmica de produção e reprodução da vida, que operam independentemente dos desejos e das intenções dos indivíduos singulares. O objetivo dessa sociedade, para os capitalistas, é obter lucro, através da venda de mercadorias acrescidas de valor, de mais-valor. Para os trabalhadores, o objetivo é conseguir vender a única mercadoria da qual dispõem, a sua força de trabalho, para se apropriar dos meios de subsistência necessários à vida. A dinâmica do capital é incessante e o capitalista que permanecer parado, deixará de exercer uma relação capitalista, será derrotado como capitalista e superado pelos demais. Este é o ser social atual, tendo em vista que a relação capitalista se universalizou ${ }^{6}$. O ponto chave é que

a circulação do capital é, ao contrário, um fim em si mesmo, pois a valorização do valor existe apenas no interior desse movimento sempre renovado [de compra de mercadorias para sua revenda, ou, na fórmula de Marx, D - M D']. O movimento do capital é, por isso, desmedido (MARX, 2017, p. 228).

Passemos à questão do politicismo. Por este conceito entende-se, na esteira de Tonet (2015) e Sartori (2017), que o Estado seria uma esfera privilegiada para resolução dos conflitos sociais, incluindo, aí, os conflitos ecológicos. Se a proposta adotada pelo Estado consiste em multas para empresas que poluem, em fiscalização ambiental mais rigorosa, em políticas de cunho educacional para promover a sustentabilidade ou a cidadania, isso de nada altera a questão. A posição politicista consiste em ver no Estado, uma instituição que paira acima da sociedade, como um ambiente de conciliação e acordo entre os interesses divergentes. Remeter para o Estado, para a discussão política uma suposta solução para os problemas, incluindo os problemas ambientais, é esquecer que "o poder político é o poder organizado de uma classe para a opressão da outra" (MARX; ENGELS, 2010, p. 58). Como afirma Marx nas Glosas críticas:

O Estado não pode eliminar a contradição entre a função e a boa vontade da administração, de um lado, e os seus meios e possibilidades, de outro, sem eliminar a si mesmo, uma vez que repousa sobre essa contradição. Ele repousa sobre a contradição entre a vida pública e privada, sobre a contradição entre os interesses gerais e os interesses particulares (MARX, 2010, p. 60). 


\section{Autตaคูão}

ISSN: 1984-6444 | http://dx.doi.org/10.5902/1984644436961

Os exemplos de politicismo na história não são recentes. Engels (2015), em 1872, já assinalara acerca da impossibilidade de o Estado resolver os problemas de moradia. Assim como as leis estatais se mostraram inócuas quanto a essa questão, melhorando aspectos apenas epidérmicos, tampouco as medidas estatais para contenção da poluição, os acordos internacionais, mostrar-se-ão efetivos para a questão ambiental. O que Engels escreveu sobre a moradia e a ineficácia de leis ou de ações filantrópicas se aplica hoje, mutatis mutandis, para a questão ambiental. Inclusive, pesquisadores críticos da educação ambiental constatam isso, a exemplo do trabalho de Layrargues (2002).

O trabalho de Layrargues (2002) é particularmente interessante, embora não sem ressalvas quanto ao caráter idealista do autor, pautado em um subjetivismo como resposta à questão ambiental e à sua crítica com relação ao consumismo. $\mathrm{O}$ autor parte de um pressuposto que deveria anteceder as reflexões de todos aqueles que se propõe a defender medidas políticas para qualidade do meio ambiente, incluindo, nessas medidas, a educação ambiental. E o pressuposto é analisar concretamente, incluindo dados quantificáveis, para ver em que medida certas ações, que no caso analisado por ele se referem à reciclagem, podem ser efetivas.

Segundo o autor, o discurso oficial ecológico critica o consumo insustentável, mas como reverso dessa crítica, há a afirmação de um consumo sustentável, propiciado por novas tecnologias que produzem os mesmos produtos com menor dano ao ambiente ou por produtos que sejam reutilizados, provenientes de processo de reciclagem. A incorporação de produtos oriundos da reciclagem, ou quaisquer outros que portem um selo verde do ecologicamente correto e/ou sustentável, gera um efeito anestésico na consciência, pois certos setores, incluindo ambientalistas progressistas, veriam nessas medidas uma conquista gradual de suas reivindicações em prol de uma sociedade melhor. O que se dá com uma mão, se tira com a outra; reciclar para não reduzir o consumo nem questionar as relações sociais de produção estabelecidas.

Assim nas propostas de educação ambiental que se dizem críticas, a solução, em última instância para questão ambiental é permeada pelos seguintes elementos: reciclagem, reutilização de recursos, uma educação institucionalizada fornecida pelo 


\section{F WEM

ISSN: 1984-6444 | http://dx.doi.org/10.5902/1984644436961

Estado (politicismo), a valorização do aspecto subjetivo (a consciência e os valores) em detrimento dos elementos objetivos pautado pelas relações de produção de vida (idealismo), e, por fim, a ênfase em determinados aspectos considerados como contestadores ou emancipatórios, como cidadania, esta quase sempre entendida como sinônimo de liberdade política e democracia. Sequer discutem-se aqui os aspectos problemáticos que dizem respeito ao entendimento da educação, e da educação escolar em especial, como uma instância contraditória, de lutas e disputas, sendo que essa contradição se daria em torno de projetos diferentes de sociedade. E não são poucos os trabalhos que em suas conclusões apontam a cidadania, a democracia e a mudança de valores como saídas, através da educação, para a crise ambiental.

Não é o espaço neste trabalho para aprofundarmos a crítica em relação à cidadania e à democracia como horizontes pedagógicos. Ela pode ser encontrada em autores como Tonet (1999; 2005) e Buffa et al. (2010).

Em resposta a todas as proposições que a educação ajudaria a resolver ou mesmo mitigar os problemas ambientais, podemos parafrasear Tonet (2015): não é a mudança da relação dos homens com a natureza, através de sensibilização, conscientização, que possibilitará um intercâmbio mais harmonioso com meio ambiente; antes, é compreender que a uma relação respeitosa dos homens entre si, na produção da vida humana, é que possibilitará uma relação harmoniosa com a natureza. E isso só será possível com a superação radical da sociedade atual, em uma sociedade cujo fundamento ontológico, o trabalho, seja baseado no trabalho associado, e não no trabalho alienado e na propriedade privada, como é a sociedade capitalista.

\section{Considerações finais}

O mapeamento científico da produção relacionada ao tema "concepção de educação ambiental", feito na base de dados Scopus, permitiu uma análise bibliométrica do tema que descrevesse as principais discussões da contemporaneidade e a interseção entre as áreas. Como resultado, identificou-se que 


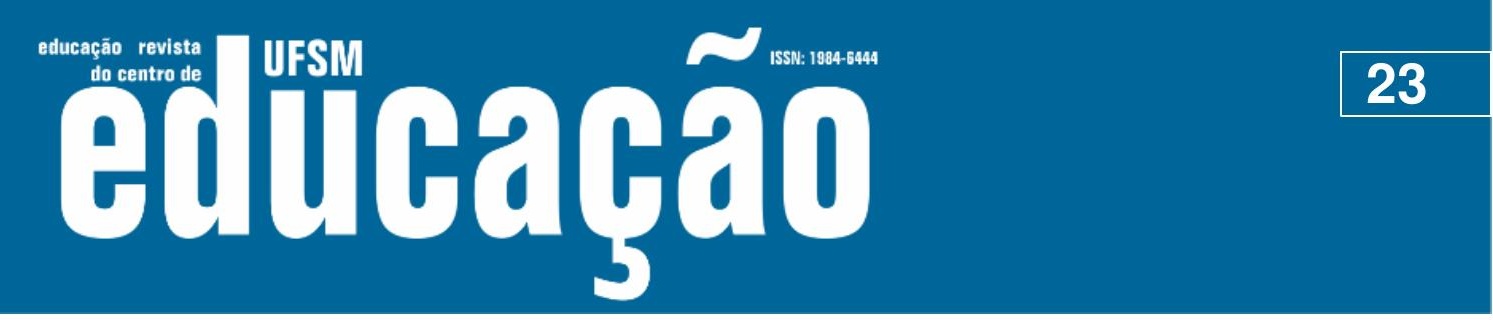

ISSN: 1984-6444 | http://dx.doi.org/10.5902/1984644436961

associado, e não no trabalho alienado e na propriedade privada, como é a sociedade capitalista.

\section{Referências}

ANDRIOLI, Antônio Inácio. A atualidade de Marx para o debate sobre tecnologia e meio ambiente. Crítica Marxista, n.27, p.11-25, 2008

BENSAÏD, Daniel. Marx, manual de instruções. Tradução de Nair Fonseca. São Paulo: Boitempo, 2013. 190 p.

BRASIL. Constituição (1999). Lei n No 9.795, de 27 de abril de 1999. Educação Ambiental: Dispõe sobre a educação ambiental, institui a Política Nacional de Educação Ambiental e dá outras providências. Brasília.

BRÜGGER, Paula. Educação ou adestramento ambiental? Florianópolis: Letras Contemporâneas, 1999.

BUFFA, Ester. Educação e cidadania burguesas. In: BUFFA, Ester; ARROYO, Miguel; CARSON, Rachel. Primavera silenciosa. Tradução de Claudia Sant'Anna Martins. São Paulo: Gaia, 2010. 327 p.

CYRINO, Eliana Goldfarb; TORALLES-PEREIRA, Maria Lúcia. Trabalhando com estratégias de ensino-aprendizado por descoberta na área da saúde: a problematização e a aprendizagem baseada em problemas. Cad. Saúde Pública, v. 20, n. 3), p. 780-788, 2004.

DANTAS, Gilson. Natureza atormentada, marxismo e classe trabalhadora. Brasília: Centelha Cultural, 2012. 144 p.

DUARTE, Newton. A individualidade para si: contribuição a uma teoria históricocrítica da formação do indivíduo. Campinas: Autores Associados, 2013. 254 p.

ENGELS, Friedrich. Sobre a questão da moradia. Tradução de Nélio Schneider. São Paulo: Boitempo, 2015. 158 p.

ENGELS, Friedrich. A dialética da natureza. Rio de Janeiro: Paz e Terra, 1979. 240 p.

FEATHER, John; STURGES, Rodney Paul. International encyclopaedia of information and library science. [2003]. Disponível em: http://mlisuok.weebly.com/uploads/2/6/9/0/26907671/international_encyclopedia_of_informati on_ind_librrary_science.pdf . Acesso em: 21 maio 2015.

FOSTER, John Bellamy. A ecologia de Marx: materialismo e natureza. Tradução de Maria Teresa Machado. Rio de Janeiro: Civilização Brasileira, 2005. 418 p. 


\section{$\sim$

ISSN: 1984-6444 | http://dx.doi.org/10.5902/1984644436961

TONET, Ivo. Educar para a cidadania ou para a liberdade? Perspectiva, Florianópolis, v. 23, n. 02, p. 469-484, jul./dez. 2005

\section{Correspondência}

Andreia de Bem Machado - Faculdade do Vale do Itajaí Mirim - Av. Getúlio Vargas, 63 - Centro, CEP 88353-900, Brusque, Santa Catarina, Brasil.

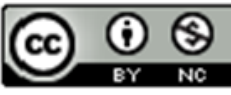

This work is licensed under a Creative Commons Attribution-NonCommercial 4.0 International (CC BY-NC 4.0)

\section{Notas}

1 Termo é oriundo da língua inglesa onde shake significa interesse, participação, risco e Holder significa aquele que possui. Assim designa um grupo ou uma pessoa que tem interesse empresa, negócio ou indústria.

2 Duas observações aqui são importantes. Evidentemente, Marx não empregou o termo desenvolvimento sustentável, mas o seu significado já estava pleno nesta formulação. E, principalmente, no contexto que Marx se refere, ele diz uma forma superior de sociedade, ou seja, não pretende impor a ideia de sustentabilidade ao modelo capitalista de produção.

3 Conforme destaca Tonet (2005), não há que se negar a positividade de valores como cidadania, liberdade, democracia e outros mais, mas entender que esses valores, na atual forma de sociabilidade, não representam o máximo possível a que o gênero humano pode chegar. E lutar por eles é lutar por uma forma que limita as potencialidades humanas possíveis.

4 Lembremo-nos da frase de Margareth Tatcher, de que a sociedade é uma abstração, o que existe são os indivíduos. https://oglobo.globo.com/opiniao/essa-coisa-de-sociedade-nao-existe-8080595.

5 Mais sobre a dialética entre objetivação e apropriação em Duarte (2013).

6 Existem relações não capitalistas no interior do capitalismo, isto é, relações, assalariadas ou não, que não produzem mais-valor. Contudo, conforme já afirmamos, a relação capitalista é o momento predominante. 